Florida International University FIU Digital Commons

FIU Electronic Theses and Dissertations

University Graduate School

11-21-1994

\title{
Alternative methods for newborn urine sample collection
}

Nancy Ann Burke

Florida International University

DOI: $10.25148 /$ etd.FI14051884

Follow this and additional works at: https://digitalcommons.fiu.edu/etd

Part of the Environmental Engineering Commons

\section{Recommended Citation}

Burke, Nancy Ann, "Alternative methods for newborn urine sample collection" (1994). FIU Electronic Theses and Dissertations. 1890. https://digitalcommons.fiu.edu/etd/1890

This work is brought to you for free and open access by the University Graduate School at FIU Digital Commons. It has been accepted for inclusion in FIU Electronic Theses and Dissertations by an authorized administrator of FIU Digital Commons. For more information, please contact dcc@fiu.edu. 


\title{
FLORIDA INTERNATIONAL UN IVERSITY
}

$$
\text { Miami, Florida }
$$

\section{ALTERNATIVE METHODS FOR NEWBORN URINE SAMPLE COLLECTION}

\begin{abstract}
A thesis submitted in partial satisfaction of the requirements for the degree of MASTER OF SCIENCE

IN

NURSING

by

Nancy Ann Burke
\end{abstract}

1994 
To: Dr. Jacquelyn Hartley

Acting Dean, School of Nursing

This thesis, written by Nancy Ann Burke, and entitled Alternative Methods for Newborn Urine Sample Collection, having been approved in respect to style and intellectual content, is referred to you for your judgement.

We have read this thesis and recommend that it be approved.

$$
\text { Dr. Janice S. Hayes }
$$

Dr. Jorge Perez

Dr. Luz Porter, Major Professor

Date of Defense: November 21, 1994

The thesis of Nancy Ann Burke is approved.

$$
\begin{aligned}
& \text { Acting Dean, School of Nursing } \\
& \text { Jacquelyn T.Hartley, PhD, RN } \\
& \text { Dr. Richard L. Campbell } \\
& \text { Dean of Graduate Studies }
\end{aligned}
$$

Florida International University, 1994 
I dedicate this thesis to my husband, Clifford, whose love and support were essential to the completion of this project. 


\section{ACKNOWLEDGMENTS}

I would like to express my appreciation to the members of my committee, Dr. Janice Hayes, Dr. Jorge Perez, and Dr. Luz Porter for their support and patience. I would also like to thank the nursing and medical staff at South Miami Hospital's NICU and the members of the Nursing Research Committee, whose willingness to facilitate this project made it all possible. I'd also like to thank Mercy Banaszak and her staff in the lab for coordinating and supporting the completion of the Directigen comparisons. Last but certainly not least, I'd like to acknowledge the contribution of the Directigen test kits from Becton Dickinson, without which I would not have been granted permission to carry out this study 
ABSTRACT OF THE THESIS

ALTERNATIVE METHODS FOR NEWBORN URINE SAMPLE COLLECTION by

Nancy Ann Burke

Florida International University, 1994

Miami, Florida

Professor Luz Porter, Major Professor

This project investigated the accuracy of laboratory results of urine samples collected from cotton balls as compared with samples collected from catheterization, preemie pampers and newborn pampers. Also, it examined the cotton ball's effect on the infant's skin upon its removal. Comparisons in test results were made concerning the Directigen test for Group B strep (GBS) and labstick analysis, using descriptive and inferential statistical analysis. The infants (21) who were tested for GBS using catheter and cotton ball samples yielded the same results.

Urine samples subjected to labstick analysis were obtained from 30 infants, the urine being extracted from preemie pampers, newborn pampers, and cotton balls placed in preemie pampers. Samples obtained from cotton balls and preemie pampers yielded equivalent results. However, significant differences were found in $\mathrm{pH}$ and specific gravity between newborn pamper samples and samples obtained from cotton balls or preemie pampers. No redness or skin breakdown was observed. 
CHAPTER

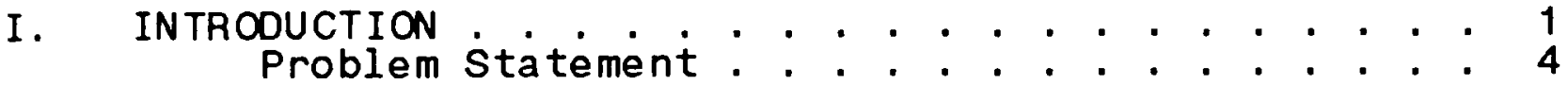

General Problem. . . . . . . . . . . . . . 4

Specific Problem . . . . . . . . . . . . . . . 4

Definitions . . . . . . . . . . . . . . . . . . 5

Significance . . . . . . . . . . . . . . . 6

i . Literature ReView . . . . . . . . . . . . . . . . . . 9

Skin Integrity .............. 9

Urine for Latex Particle Agglutination (LPA) : 10

Urine for Labstick Analysis... . . . . . . . 11

Summary . . . . . . . . . . . . . . . . . . 11

Operational Definitions . . . . . . . . . . . . 14

III. METHODOLOGY . . . . . . . . . . . . . . . . . . . . 16

Research Design. . . . . . . . . . . . . . . . 16

Research Setting . . . . . . . . . . . . . . . 16

Sample .. . . . . . . . . . . . . . . . . . . 16

Instruments . . . . . . . . . . . . . . . . . . 17

Method of Data Collection . . . . . . . . . . 18

Ethical Considerations . . . . . . . . . . . . 21

Data Analysis... . . . . . . . . . . . . . 21

IV. RESULTS . . . . . . . . . . . . . . . . . . . . . 23

Characteristics of the Sample . . . . . . . . . 23

Findings . . . . . . . . . . . . . . . . . . . 24

Skin Integrity . . . . . . . . . . . . . . . 24

Latex Particle-Agglutination . . . . . . . . . 24

Labstick Analysis-Biochemical . . . . . . . 25

Labstick Analysis-PH and Specific Gravity: : 25

V. DISCUSSION . . . . . . . . . . . . . . . . . . . . . 35

Limitations . . . . . . . . . . . . . . . . . . 36

Future Research . . . . . . . . . . . . . . . 38

Implications . . . . . . . . . . . . . . . . . 39

LIST OF REFERENCES . . . . . . . . . . . . . . . . . . . 41

APPENDIX . . . . . . . . . . . . . . . . . . . . . . . 44

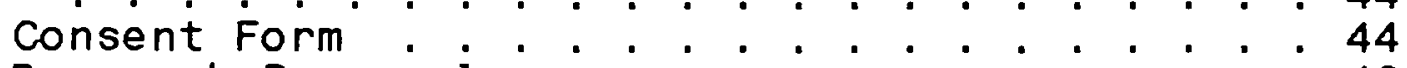

Research Proposal . . . . . . . . . . . . . . . 46

URC Approval . . . . . . . . . . . . . . . . . 47

IRB Approval . . . . . . . . . . . . . . . . . 48 


\section{LIST OF TABLES}

I. Comparison of $\mathrm{PH}$ Values Across Sampling Techniques . 27

II. Comparison of Specific Gravity Across Sampling Techniques . . . . . . . . . . . . . . . . 28

III. Extraneous Variables and Their Correlations on Preemie Pampers and Cotton Ball Samples . . . . . 30

IV. Extraneous Variables and Their Correlations on Newborn Pamper Samples. . . . . . . . . . . . . . . 32

V. Comparisons for Subjects Greater Than Two Days of Age: Urine PH and Specific Gravity . . . . . 33

VI. Comparisons for Subjects With Volumes Greater Than $20 \mathrm{~mL}$ : Urine $\mathrm{PH}$ and Specific Gravity . . . . . 34 
CHAPTER ONE

Introduction

This study investigated alternative safe and accurate methods of obtaining routine urine samples from neonates. The goal was to maintain skin integrity and to prevent infection and pain that may be experienced with methods currently utilized to collect urine samples, without sacrificing accuracy.

Routinely, a quantity of urine must be obtained from infants cared for in the newborn intensive care unit (NICU). In general, this urine is tested for latex-particle agglutination (LPA) and labstick analysis. The LPA tests for antigens to Group B Streptococcus(GBS), which is an organism known to cause sepsis in the newborn period. This test is done to facilitate early detection and treatment of neonatal sepsis (Sanchez, Seigel, Cussion and Trekeld, 1990). The labstick analysis measures the specific gravity and $\mathrm{pH}$, and checks for the presence of leukocytes, nitrite, urobilinogen, bilirubin, blood, protein, ketones, and glucose (Boehringer Mannheim Diagnostics, 1993). It is useful to assess hydration and guide treatment of the newborn.

Urine bags may be employed to collect this urine. They are frequently applied with a solution to enhance adhesion, such as tincture of benzoin. This is contraindicated in the 
preterm infant (Kuller, 1984) (Kuller and Tobin, 1990). These infants have been categorized as those with post-conceptual age up to 37 weeks (Merenstein and Gardner, 1985). Literature reports the skin of these infants to be thinner than that of mature infants and adults (Kuller, 1984) (Kuller and Tobin, 1990) in the first two weeks of life (NAACOG, 1992). Their thin skin along with their greater skin surface area to body mass ratio creates potential for absorption and toxicity when exposed to these solutions (Kuller, 1984) (Kuller and Tobin, 1990). The use of adhesives in this population creates a problem via the removal of the adhesive and subsequent removal of fragile skin (NAACOG, 1992) (Fox, 1992). Current literature recommends restricting the use of excessive adhesives to alleviate this problem (Tobin, 1984) (Kuller and Tobin, 1990), hoping to maintain skin integrity, which protects against infection in an already immune-compromised patient.

Ahmad, Vickers, Campbell, Coulthard and Pedler (1991) describe the use of the urine collection bag in newborns to be associated with inadequate adhesion and discomfort. Despite careful application of the urine bag (even with the use of benzoin), the sample is often lost. In my many years of experience, I have seen several denuded areas resulting from the (repeated) application of these urine collection devices, even in full term infants.

Diaper aspiration with a syringe has been employed for many years, and some studies have examined the validity of 
this sampling. Urine aspirated from Procter and Gamble ( $P$ \& $G$ ) premature disposable diapers (preemie pampers) has been studied and determined to yield accurate results with respect to labstick analysis (Suri, 1988), (Stebor, 1989), (Lyband, Medoff-Cooper and Munro, 1990), (Schlager, Dunn, Dudley and Lohr, 1990). Recent improvements in the absorbency of disposable diapers has impaired the ability to aspirate urine, leading some practitioners to tear open the protective layer of the diaper, place portions of the absorbent layers into the barrel of the syringe, replace the plunger and attempt to compress the urine out of the syringe (Wong and Whaley, 1990). Many times the absorbent matter comes through with the urine. One cannot help but wonder what effect this has on the test results. Research has not addressed the accuracy of these testing methods. Additionally, the diaper aspiration method is often not suitable to the collection of large amounts of urine required for the tests routinely ordered.

Another method used to collect urine samples is the use of a lubricated 5 french tube to catheterize the urinary meatus and obtain a specimen from the bladder using aseptic technique. This method is successful only if there is urine present in the bladder and the infant has not been stimulated to void during the cleaning process used to prepare the site of insertion. Straight catheterization of the bladder can result in trauma, swelling and infection (Fletcher and MacDonald, 1993). 
Lastly, the practitioner can elect to perform a suprapubic tap, which involves needle aspiration of urine in the bladder through the abdomen. Timing is also critical, as the bladder must be full to succeed. This method also carries the risk of infection, hematuria, hematoma, perforation of the bowel or pelvic organs, peritonitis, abdominal wall abscess and bacteremia (Barkemeyer, 1993).

This study tested an alternative method, specifically the aspiration of urine from a cotton ball that has been placed near the urinary opening inside of a pamper. It attempted to collect the urine samples without impairment of skin integrity, without increasing the exposure to infection, and without pain and trauma. Additionally, accuracy of the test results was investigated.

\section{Problem statement}

\section{General Problem:}

The general problem was to determine the safety and accuracy of an alternative method of urine collection from newborns. In this study, the alternative method was the cotton ball aspiration (CBA) method.

Specific Problems:

1. To what extent is the CBA method of urine collection safe with respect to maintenance of skin integrity? 
2. To what extent are the results obtained from the CBA method reliable?

a. Are the results of the LPA test of CBA-obtained samples equivalent to the LPA test results of catheterobtained samples?

b. Are the labstick results from the CBA method equivalent to those obtained from the preemie pamper?

c. Are the labstick results from the newborn superabsorbent disposable diaper equivalent to those obtained from the preemie pamper?

This study tested the cotton ball aspiration method for collecting urine samples in order to eliminate the trauma and discomfort that may occur with the urine bag, catheter or suprapubic tap methods. Additionally, the results of the laboratory tests were examined to determine the accuracy of the CBA method for urine sample collection.

\section{Definitions:}

Diaper: $P$ \& $G$ disposable pampers (preemie or newborn size as appropriate)

Urine bag: Hollister's sterile newborn or preemie size urine collection bag.

Latex-particle agglutination: a test for the presence of antigen involving group B streptococcus. 
Labstick analysis: urine tested for $\mathrm{pH}$, specific gravity, leukocytes, nitrite urobilinogen, bilirubin, blood, ketones, protein, and glucose.

\section{Significance}

The collection of urine from the newborn has historically posed a problem. When urine is collected for LPA, the use of urine collection bags has become the standard method, with some practitioners opting for straight catheterization or needle aspiration of the bladder. The risks of these methods have already been described. It is of paramount importance that we determine the safest, least traumatic method to collect samples.

$P$ \& G preemie pampers have been studied with respect to labstick analysis on samples collected via syringe aspiration method. The results obtained were equivalent to urine bag sample results. As hospitals attempt to cut costs, diaper brands are arbitrarily changed without consideration for the impact on urine analysis. While this may contain costs, it does not assure accuracy of the urine tests routinely performed. A cotton ball placed at the urinary meatus can be an easy, non-invasive method to collect up to $15 \mathrm{~mL}$. of urine. It would be helpful to know that this technique could yield accurate results.

In this study, the results of urine samples collected from cotton balls were examined and compared to those 
collected by catheterization and diaper aspiration method. If the CBA method can be supported, the trauma otherwise associated with urine collection can be avoided.

Maintenance of neonates' skin integrity is particularly crucial to protect them from infection. Their skin's tendency to break down and become infected increases with their degree of prematurity. This makes any effort to maintain their intact skin of paramount importance (Kuller and Lund, 1993).

Additionally, the cost factor is impressive. I have employed one inch cotton balls to aspirate and test urine. This compares with the cost of the urine bag sampling method, resulting in a 738 savings, assuming the specimen can be collected in the first bag applied, which is not always the case. For those practitioners who prefer the bladder catheterization method, the CBA method would amount to a $96 \%$ savings. This savings can be significant in a high volume setting. This does not even take into account the savings in skin care products or therapies that may be needed to treat the skin breakdown or infection that has a high likelihood to result from the standard methods. The maintenance of skin integrity, avoidance of exposure to toxic substances, and the cost factor all favor the CBA method.

The limitation of the CBA method is the potential for stool contamination, but this is not a common problem in the first days of life in the preterm infant. If there is stool present, it often contaminates the bag specimen as well. 
Ultimately, this method may be utilized in older infants in out-patient settings. It may not replace current methods all together, but may be a valid alternative. 
CHAPTER TWO

Literature Review

\section{Skin Integrity}

Kuller (1984) describes the importance of skin integrity, which protects the internal organs from infection and foreign substances, participates in thermoregulation, provides tactile stimulation, stores fat and aids in maintenance of fluid and electrolyte balance. Tobin (11984) goes on to describe the large surface area to body weight ratio and increased skin permeability which are factors that allow the infant to absorb larger quantities of topically applied substances than adults, predisposing them to toxicity. This is especially true of the preterm infant, due to their thin outer layer of skin. Additionally, the bond between the dermis and the epidermis in preterm infants is weakened, resulting in accidental removal of the epidermal layer with the removal of adhesives. According to Isaacs and Moxon (1991), "The skin of the newborn, and particularly that of the preterm infants, is thin and susceptible to trauma both during delivery and subsequently. Skin sepsis is common in the neonatal period, " and they go on to describe the most common pathogens involved. The importance of skin care is further emphasized by McCourt (1994) in her document on the incidence of infection in the very-low-birthweight infant. She sites poor skin integrity as one factor in 
the high incidence of infection, posing a major cause of morbidity and mortality in this patient population. She describes the newest concern, Candida sepsis, as one of the major organisms responsible for this problem, and postulates the port of entry for this organism to be breaks in the skin. She, along with Kuller and Tobin (1990), and Kuller and Lund (1993), state that diligent skin care is a priority, and that the avoidance of adhesives, adhesive enhancers such as tincture of benzoin, and urine bags is preferable whenever an alternative can suffice.

\section{Urine for Latex-Particle Agglutination}

In an article by Sanchez, Seigel, Cussion and Treikeld (1990), the LPA test has been reported to be $88-100 \%$ sensitive and 81-100\% specific for the detection of GBS. They looked at the significance of a positive urine LPA test for GBS in the presence of a negative blood culture. The rate of what they considered false positives (positive LPA with negative blood culture) ranged from 0-16.9\%. They had four hypothesis for this phenomenon, and ultimately concluded their study by stating that all the infants who had a positive LPA and negative blood culture were born to mothers colonized with GBS. They determined that there was the likelihood that the urine collected from a bag specimen represents colonization and not active infection, and that bladder aspiration or urinary catheterization will improve the specificity of the 
test. This has led many practitioners to prefer these methods. The authors also suggest that a more effective asepsis of the perineum will improve the specificity. This study attempted to validate this option and combine it with the CBA method, allowing the safer, less invasive method to become practice.

\section{Urine for Labstick Analysis}

In 1988, Suri addressed values of $\mathrm{pH}$, specific gravity, glucose, ketones and protein in urine aspirated from $P$ \& $G$ disposable diapers as compared with samples aspirated from urine collection bags in 30 infants. The examiner noted the inability to use super absorbent diapers in the study. The study supported the validity of the results on urine aspirated from this brand of diaper. Reams and Dean (1988) had similar findings among the 25 samples they compared using diaper aspiration (brand not specified) versus urine bag specimens. In 1991, Beeram and Dhanireddy looked at specimens from 17 samples drawn from preemie pampers ( $P \& G$ ) specifically, and they also found the results equivalent with respect to blood and the above mentioned parameters. There was also a study carried out by Hutton and Schreiner in 1980 that looked at the specific gravity and glucose values of urine aspirated from a cotton ball, comparing the results to a sample obtained from a preemie pamper ( $P \& G$ ) and found them to be equivalent.

Stebor (1989) and Lybrand, Medoff-Cooper and Munro (1990) studied the effects of time passage in the typical NICU 
environment on the urine sample, and concluded that the specific gravity measurements in closed disposable diapers (brand not specified) were equivalent to bag obtained specimens over a 2-4 hour period. Open diapers exposed to the environment had a dramatic change in specific gravity ( Hutton and Schreiner, 1980) (Cooke, Werkman and Watson, 1989). In 1992, Fox described the same phenomenon, noting a high degree of evaporation that can occur in a disposable diaper left open to environmental factors. These studies emphasized the need to protect the diaper/ cotton ball from the effects of the environment by keeping it closed.

\section{Summary}

The first component, skin integrity, was addressed in this study by the observation of the diaper area upon removal of the cotton ball placed for sampling. Intact skin with no observable redness or drainage enabled the investigator to state there was no observable impact on the skin from the placement of the cotton ball. The hypothesis tested in this case was that there was no observable impact on the skin of the newborn from placement of a cotton ball for urine collection.

The next issue addressed involved the accuracy of the results obtained from the cotton ball aspiration technique when compared with the results obtained from the bladder catheterization method. Previous studies suggested that a more 
thorough cleansing of the diaper area would yield more accurate results, thus this was implemented. The hypothesis tested in this situation was that urine obtained via the CBA method yielded the same results as urine obtained via the bladder catheterization technique, subsequent to thorough cleansing of the diaper area.

The CBA method was then examined to evaluate the results of labstick analysis. Since past researchers have determined urine aspirated from the $P \& G$ premature pampers gave accurate results, the simultaneous sampling and comparison of the two methods allowed the investigator to determine the accuracy of the CBA method. The hypothesis was that urine obtained via the CBA method yielded the equivalent results when compared with urine obtained via the preemie pamper aspiration method.

Lastly, the samples obtained from the preemie pampers were compared to samples aspirated from newborn superabsorbent pampers. The sample was obtained from the newborn super-absorbent pamper by loading the absorbent materials into the barrel of a syringe and compressing the barrel until there emerged a Iiquid to test (Wong \& Whaley, 1990). It is possible that the material that emerged was a mixture of urine and diaper contents. The hypothesis evaluated was that urine aspirated from the preemie pamper and the super-absorbent pamper yielded equivalent results. 


\section{Operational Definitions:}

Subjects: newborns who are 28 days of age or less when corrected for gestational age (weeks of gestation plus age) cared for in South Miami Hospital's NICU.

Preemie pampers: Procter and Gambel premature disposable diapers.

Newborn pampers: Procter and Gambel newborn disposable diaperphase I, 8-14 lbs.

Cotton ball: standard non-sterile .75-1.5 inch cotton ball. Syringe: 3-6 cc sterile, unused monojet syringe.

Iodine prep: 3 of the 10\% iodine swabs utilized to cleanse the area surrounding the urinary opening.

Water: Sterile $3-4 \mathrm{oz}$. bottles of water from Ross Labs or Mead Johnson.

LPA: laboratory test, also referred to as Directigen, utilized for the direct qualitative detection of antigens to Group B Streptococcus in urine (Becton Dickenson, 1993).

Labstick analysis: Utilizing the chemstrip 10 with SG urine test strips from Boehringer Mannheim Diagnostics (1990), urine is assayed for specific gravity, leukocytes, nitrite, Ph, protein, glucose, ketones, urobilinogen, bilirubin, and blood.

Preemie pamper aspiration: direct aspiration of urine from the pamper with a syringe without dissecting the core of the pamper. 
Newborn pamper aspiration: aspiration of urine from the pamper via placement of the absorbent material in the core of the diaper into a 3-6 cc syringe and compressing the material with the barrel of the syringe, extracting the urine.

Cotton ball aspiration method: aspiration of urine from a cotton ball that has been placed near the urinary opening inside of a closed pamper.

Lubricant: sterile 2.7 gram. foil pouches of water-soluble lubricant.

Bladder catheterization: instillation of a 5 french hollow tube into the bladder under sterile conditions for purposes of obtaining urine. 


\section{CHAPTER THREE}

\section{Methodology}

\section{Research Design}

The research design was quasi-experimental, based on a convenience sampling technique. The independent variable was the urine sampling method, consisting of bladder catheterization, CBA, preemie pamper aspiration and newborn super-absorbent pamper aspiration. The dependent variables were the skin condition upon removal of the cotton ball, the LPA results and the labstick analysis results.

\section{Research setting}

The setting of this study was a 22-bed, level-2 NICU unit, with the population consisting of infants admitted from birth to 28 days of life. The most common admitting diagnoses were Prematurity, Respiratory Distress Syndrome and Rule Out Sepsis.

Sample

The sampling plan was as follows:

1.) Skin Integrity: all infants with intact skin whose parents consented to their participation in this study were included. 
2.) Latex-Particle Agglutination: the first 20 infants who were admitted to the NICU for a septic work-up (blood culture, $C B C$ and urine for LPA), whose parents consented to their participation in the study were included.

3.) Labstick Analysis: the first 30 clinically stable infants cared for in the NICU, whose parents consented to their participation in this study, and whose urine samples could be collected within a 12 hour period of time were included. Those infants with renal anomalies, urinary tract infections, and those who were receiving transfusions of blood or blood products were eliminated from the study at that time.

\section{Instruments}

The tool utilized for the testing of urine for LPA was the Directigen Meningitis Individual Tests. The component that tests for GBS is reported to be $100 \%$ specific for that organism (Becton Dickinson, 1993) and 88-1008 sensitive (Sanchez et al, 1990). The controls and preparation of the sample were crucial to the accuracy of the results and were clearly spelled out in the manufacturer recommendations. The laboratory personnel were responsible to carry out these controls.

The labstick analysis was carried out using Boehringer Mannheim Diagnostic Chemstrip 10 with SG urine test strips. The reagent strips did not require any calibration, and as long as 
they were maintained in their closed aluminum vial with their appropriate drying agent they remained suitable for use. There was an expiration date applied for additional control. According to the manufacturer, the specific gravity measurement was reported to be accurate within .005, unless the $\mathrm{pH}$ was over 7 , then .005 was added to the figure to assure accuracy of measurement (per manufacturer instructions). The values for $\mathrm{pH}$ were within 1 unit.

Leukocyte measurements were 97.28 sensitive and 90.18 specific. Nitrite was reported to have a frequency of false positives < 18. Protein tested more sensitive to albumin, with concentrations of $6 \mathrm{mg} / \mathrm{dL}$ or greater producing a color change in $90 \%$ of urine tested. Glucose concentrations of 40 $\mathrm{mg} / \mathrm{Dl}$ produced positive results in $90 \%$ of the urine tested. Ketone in urine produced a positive reaction in $90 \%$ of the urine tested. Urobilinogen reacted at $0.4 \mathrm{mg} / \mathrm{Dl}$, and bilirubin reacted at $0.5 \mathrm{mg} / \mathrm{Dl}$ in $90 \%$ of the case. Blood determination was reported to be $90 \%$ accurate. (Boehringer Mannheim Diagnostics, 1990).

\section{Method of Data collection}

In order to determine if there was any impact on the infant's skin resulting from the placement of the cotton ball at the urinary opening, an observation was made prior to and upon removal of the cotton ball. One infant who had skin 
impairment prior to the application of the cotton ball was eliminated from this part of the study.

The nurse carried out the urine collection for LPA in the standard manner, by cleansing the area with $10 \%$ iodine solution and inserting a sterile 5 french hollow tube lubricated with sterile lubricant into the urinary opening until urine is obtained. The catheter was then withdrawn and the area cleansed with sterile water. The cotton ball was placed at the urinary opening for the collection of a comparison sample, which was aspirated from the cotton ball with the subsequent voiding. In the event that the specimen was contaminated with stool, the area was prepared with the iodine prep swabs and cleansed with sterile water for the collection of the second cotton ball sample. The samples were processed in the SMH laboratory according to manufacturer's recommendations. The results that were recorded in the medical record and reported to the physician were from the catheter method, as it was the standard at SMH.

Each infant who participated in the labstick analysis portion of the study was tested using all three methods, preemie pamper, cotton ball and newborn pamper aspiration methods, with the order of the method assigned randomly. Those with even numbered medical records were assigned to the preemie pamper and CBA method first, via coin toss. Those with odd numbered medical records were assigned to the newborn pamper method first, by process of elimination. The infants 
had the assigned diaper applied and maintained closed. Within a three hour interval, the urine was extracted and labstick analysis carried out by the nursing staff involved.

Any sample contaminated with stool was discarded. The preemie pamper did not have the core disturbed, as urine was readily aspirated from this type of diaper. The cotton ball sample was also aspirated and sampled at this time.

The newborn pamper was not conducive to the aspiration of urine, and the method described by Wong and Whaley (1990) of loading the super-absorbent gel materials into the barrel of a syringe and compressing the liquid to test was used. The three urine samples required of each subject were all collected within twelve hours, in order to attempt to eliminate some of the changes in the values that can occur with time.

The labstick analysis was done using Boehringer Mannheim Diagnostic Chemstrip 10 with SG urine test strips. After the urine was aspirated from the source, it was applied to the labstick in a manner that saturated the reagent paper but did not run over onto the other reagents. The results were compared to the reagent bottle's chart in the 60-120 second time period following application. The results that we re recorded in the medical record were the ones obtained from the pamper, as that was the accepted standard at SMH. 


\section{Ethical Considerations}

The population involved in this study has been identified as vulnerable and their rights must be protected. According to the American Nurses Association (1985), these rights include the right to freedom from injury, the right to privacy and dignity, and the right to anonymity. These rights were carefully considered, and the process of informed consent required of the legal guardians to participate in this study put in place the necessary safeguards. The University Research Council at Florida International University and the Institutional Review Board at South Miami Hospital, as well as the Medical Director and the Nurse Manager of the NICU reviewed this study proposal and approved the design.

\section{Data Analysis}

The data were collected and analyses carried out using descriptive and inferential statistics as appropriate. For skin assessment, descriptions such as intact, reddened and impaired were used to categorize any change that was observed.

For the LPA component of the study, a correlation of .90 or greater was desirable. This was based on the high importance placed on the early detection and treatment of Group B Streptococcus infection in the newborn.

The data collected for labstick analysis were broken down into biochemical analysis, specific gravity and $\mathrm{pH}$ results. The biochemical analysis had a low incidence of positive 
results and frequencies were noted for these results. The results of the $\mathrm{pH}$ and specific gravities were analyzed using $t$-tests for paired samples. $\leq .05$ was considered a significant difference.

The Pearson Product-Moment Correlation Coefficient was utilized to describe the relationships that exist between the same parameters. A $p \leq .05$ and a correlation $>.7$ was considered significant for this portion of the study, since these values should remain theoretically equivalent across the sampling techniques. A lesser threshold was acceptable when compared with the threshold set for LPA, based on changes that can occur over the 12 hour sampling period. Additionally, these results are valuable but treatment based on the results are not necessarily life-threatening.

The possibility that the gestational age, chronological age, sex of the infant or volume of urine in the diaper may have had an impact on the results was investigated. These parameters were recorded and analyzed using Pearson ProductMoment correlations, t-tests for paired samples (for those sample sets with at least 20 available subjects), or the Wilcoxin Matched- Pairs Signed-Ranks Test (for sample sets less than 20). The same parameters were used to estimate significance of the correlations and differences. 


\section{CHAPTER FOUR}

Results

Characteristics of the sample

Five of the subjects participated in both the LPA and labstick analysis portion of this study, resulting in a total sample of 45 infants who were assessed for skin integrity. The population was 66.68 male and $33.3 \%$ female. Their ethnic distribution depicted 46.68 Hispanic, 26.68 Caucasian, 208 Black American, 4.48 Haitian and 2.28 Mixed. They ranged in age from 27.6 weeks gestation to 15 days when corrected for gestational age.

There were 21 infants who were sampled for LPA comparison. Sixty percent were male, $40 \%$ were female. Concerning ethnicity, $50 \%$ were Hispanic, $30 \%$ were Caucasian, 158 were Black American and $5 \%$ were Haitians. All of these infants were sampled within 3 days of their birth. Of those infants sampled, one test using the CBA method was reported as not interpretable and this infant was deleted from the study. This was described by the director of the microbiology laboratory as being the result of something in the urine or controls that interfered with the test.

The population sampled in the labstick analysis portion of the study consisted of 30 infants being cared for in the NICU at SMH. Males represented 66.6 \% and females, 33.3\%. 
Ethnic distribution was 408 Hispanic, 33.3\% Caucasian, 208 Black American, 3.38 Haitian and $3.3 \%$ mixed. The ages ranged from 27.6 weeks gestation to 15 days when corrected for gestational age, with a mean of 35.7 weeks.

\section{Findings}

\section{Skin Integrity}

Each infant was examined upon removal of the cotton ball and found to have no signs of redness or loss of skin integrity. This supports the hypothesis that the cotton ball inside the pamper for urine collection would not have an adverse effect on the skin of the newborn.

\section{Latex Particle-Agglutination Test Results}

When the urine was tested for LPA, there was noted to be a correlation of 1.0 , with all 3 of the GBS positive infants being positive with both samples and all 17 of the GBS negative infants being negative with both samples. This supports the hypothesis that the urine obtained via CBA method yielded the same results as the urine obtained via the catheterization method, subsequent to thorough cleansing of the diaper area.

Supplemental cultures were available for some of the subjects. Seven of the mothers were cultured (placenta, lochia, or vaginal cultures) with 3 of them being positive for 
GBS (15\% of the sample). The blood cultures performed on the babies revealed 2 out of the 3 infants with positive LPA had positive blood cultures.

\section{Labstick Analysis - Biochemical Parameters}

The results of the labstick analysis for bilirubin, ketones, leukocytes, nitrites, and urobilinogen were negative across all sampling methods and did not lend themselves to further analysis. When looking at the data, there were some similarities in the few positive results. Both infants who had positive values for blood were consistent across each sampling method. Of the 2 infants who had glucose present, 1 was consistently positive while the other was positive only with the preemie pamper and cotton ball method. Of the 5 infants who tested positive for proteinuria, only 4 were positive with the cotton ball and 2 with the newborn pamper sampling.

Labstick Analysis-PH and Specific Gravity

Comparisons of the mean values for $\mathrm{pH}$ and specific gravity across the sampling methods were carried out using $t$ tests for paired samples. There was a significant difference noted when preemie pamper or cotton ball samples were compared to the newborn pamper samples. A power analysis on the data was conducted and results revealed 88.6 to $99.5 \%$ power. There was no significant difference noted for $\mathrm{pH}$ and specific 
gravity when cotton ball and preemie pamper samples were compared. The findings are depicted in Tables 1 and 2 .

These data supports the hypothesis that urine collected via CBA method yielded equivalent results when compared with urine collected via preemie pamper aspiration method. There is some support for the newborn pamper aspiration method related to the presence or absence of blood, bilirubin, glucose, ketones, leukocytes, nitrite, protein and urobilinogen as compared with the preemie pamper samples. While it was hypothesized that urine aspirated from preemie pampers and super-absorbent newborn pampers yielded equivalent results with respect to $\mathrm{pH}$ and specific gravity, the data did not support this. Power analysis with respect to this difference was $99.5 \%$. 
Table One: Comparisons of PH Values Across Sampling Methods

\begin{tabular}{||l|c|c|c|c|c|c|}
\hline $\begin{array}{l}\text { SAMP LING } \\
\text { ME THOD }\end{array}$ & N & MEAN PH & SD & $\begin{array}{c}t- \\
\text { VALUE }\end{array}$ & df & $\begin{array}{c}2 \text {-TAIL } \\
\text { SIG. }\end{array}$ \\
\hline COTTON BALL & 30 & 6.0667 & .640 & & & \\
$\begin{array}{l}\text { PREEMIE } \\
\text { PAMPER }\end{array}$ & 30 & 6.0000 & .695 & 1.44 & 29 & .161 \\
\hline
\end{tabular}

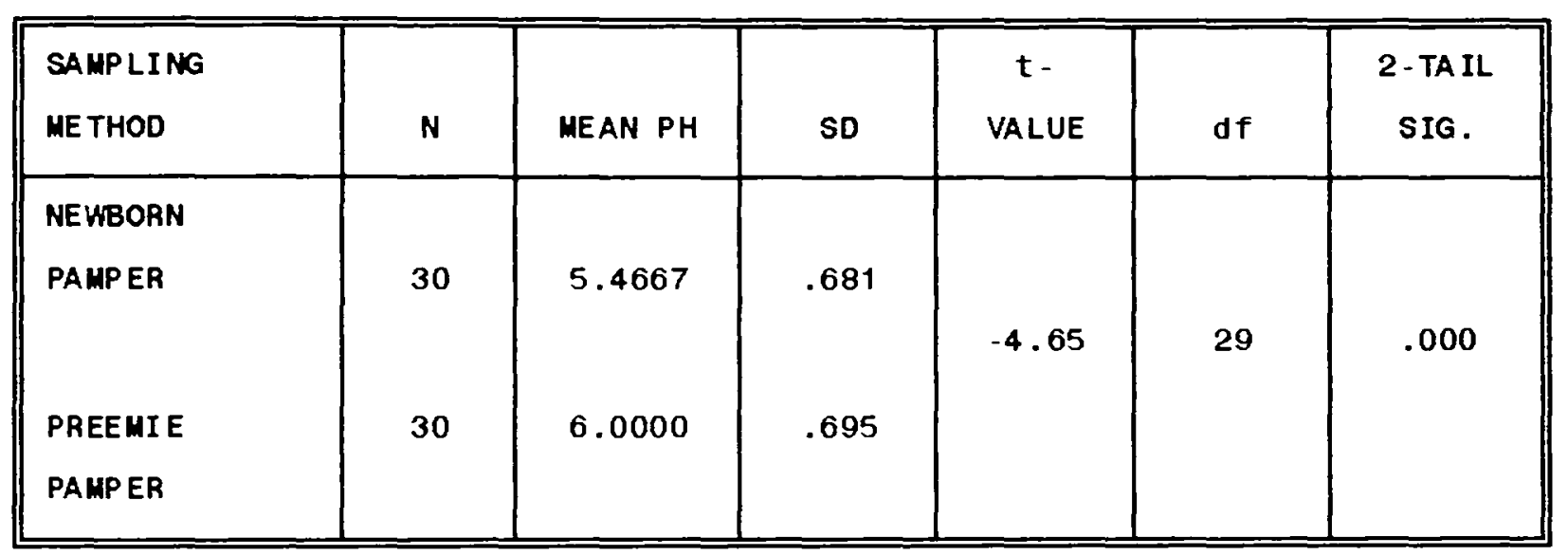

\begin{tabular}{|c|c|c|c|c|c|c|}
\hline $\begin{array}{l}\text { SAMPLING } \\
\text { ME THOD }\end{array}$ & $\mathbf{N}$ & MEAN PH & SD & $\begin{array}{c}t- \\
\text { VALUE }\end{array}$ & $d f$ & $\begin{array}{c}\text { 2-TA IL } \\
\text { SIG. }\end{array}$ \\
\hline COTTON BALL & 30 & 6.0667 & .640 & 5.29 & 29 & .000 \\
\hline $\begin{array}{l}\text { NEWBORN } \\
\text { PAMPER }\end{array}$ & 30 & 5.4667 & .681 & & & \\
\hline
\end{tabular}

*Normal newborn values for pH range from 5-7, with an average of 6 (Behrman and Vaughan, 1987). 
Table Two: Comparison of Specific Gravity (SG) Across Sampling Methods

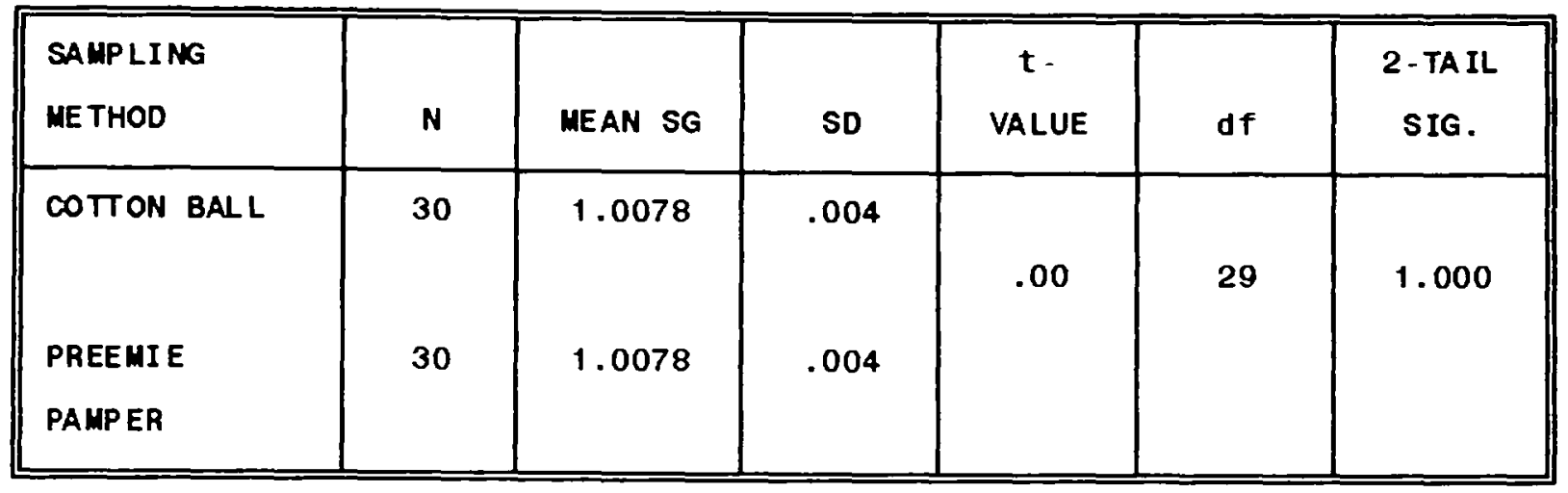

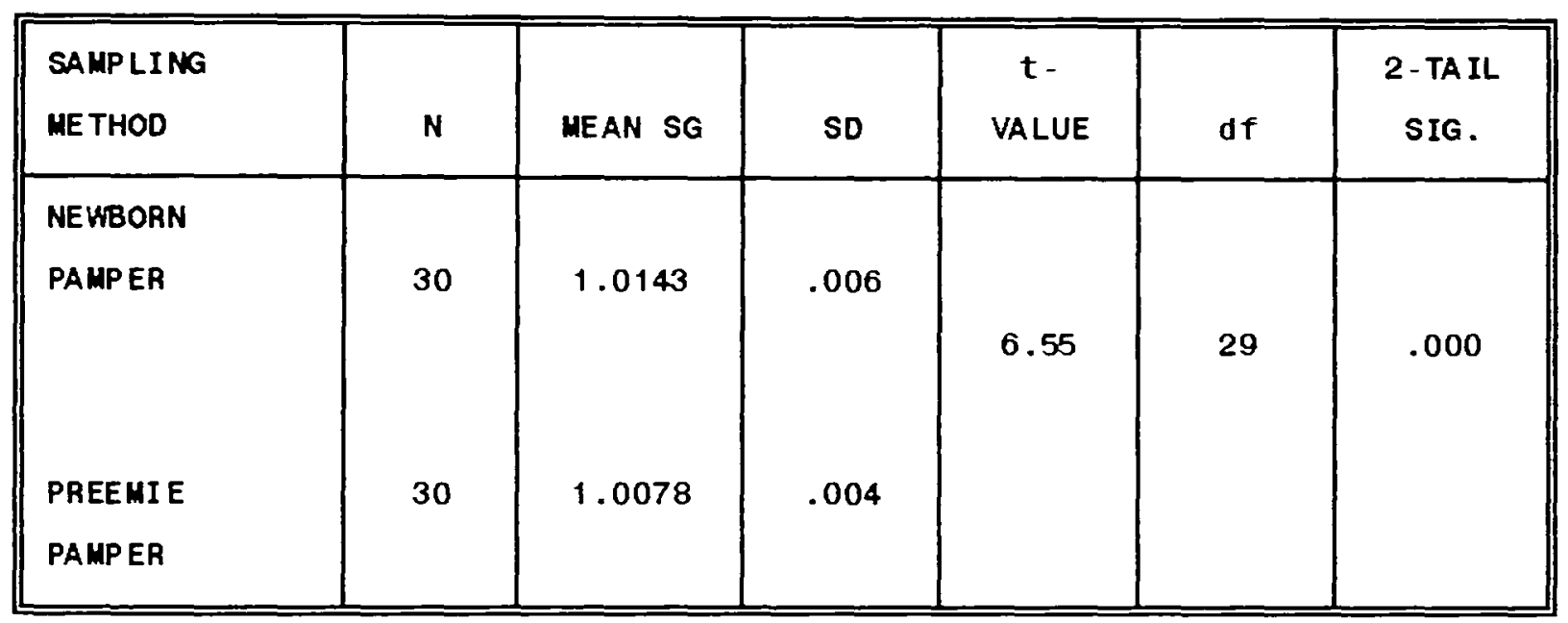

\begin{tabular}{|c|c|c|c|c|c|c|}
\hline $\begin{array}{l}\text { SAMPLING } \\
\text { ME THOD }\end{array}$ & $\mathbf{N}$ & MEAN SG & SD & $\begin{array}{c}t- \\
\text { VALUE }\end{array}$ & $d f$ & $\begin{array}{c}2 \text {-TAIL } \\
\text { SIG. }\end{array}$ \\
\hline COTTON BALL & 30 & 1.0078 & .004 & -6.97 & 29 & .000 \\
\hline $\begin{array}{l}\text { NEWBORN } \\
\text { PAMP ER }\end{array}$ & 30 & 1.0143 & .006 & & & \\
\hline
\end{tabular}

1.010, with a slight increase in the presence of glycosuria or proteinuria (Merenstein and Gardner, 1985). 
The extraneous variables were examined using Pearson Product-Moment correlation. The infant's gestational age, chronological age, preemie pamper results for $\mathrm{pH}$ and specific gravity, volume of urine present, and cotton ball results for $\mathrm{pH}$ and specific gravity were compared. The findings reveal a correlation coefficient of .9407 ( $N=30, p=.000)$ between the specific gravity of the preemie pamper and the cotton ball samples, and a correlation coefficient of .931 ( $N=30, p=.000)$ between the $\mathrm{pH}$ results of both sampling methods. Power analysis reported on these data were reported to be $99.5 \%$. Chronological age and gestational age had a negative correlation $(-.6832, N=30, p=.000)$, which is logical, since the lower the gestational age, the longer it is likely the infant must remain in the hospital and the older he will be when he is stable enough to participate in this study. All other comparisons had correlation coefficients $<.7$ and were not regarded as significant (see Table 3 ). The data supports the hypothesis that urine obtained for labstick analysis via the CBA method yielded equivalent results when compared with urine obtained via the preemie pamper aspiration method. 
Table Three: Extraneous Variables and Their Correlations on Cotton Ball and Preemie Pamper Samples $(n=30)$

\begin{tabular}{|c|c|c|c|c|c|c|}
\hline VARI ABLES & $\begin{array}{l}\text { COTTON } \\
\text { BALL PH }\end{array}$ & $\begin{array}{c}\text { COTTON } \\
\text { BALL } \\
\text { VALUE }\end{array}$ & $\begin{array}{l}\text { COTTON } \\
\text { BALL } \\
\text { SPECIFIC } \\
\text { GRAVITY }\end{array}$ & $\begin{array}{c}\text { GEST AT IONAL } \\
\text { AGE }\end{array}$ & $\begin{array}{l}\text { CHRONO- } \\
\text { LOGICAL } \\
\text { AGE }\end{array}$ & $\begin{array}{l}\text { PREEM IE } \\
\text { PAMPER } \\
\text { SPECI FIC } \\
\text { GRAVITY }\end{array}$ \\
\hline $\begin{array}{l}\text { COTTON BALL } \\
\text { PH }\end{array}$ & & $\begin{array}{c}.0693 \\
P=.716\end{array}$ & $\begin{array}{l}-.1486 \\
P=.433\end{array}$ & $\begin{array}{c}.0913 \\
P=.631\end{array}$ & $\begin{array}{l}-.0389 \\
P=.838\end{array}$ & $\begin{array}{l}-.2320 \\
P=.217\end{array}$ \\
\hline $\begin{array}{l}\text { COTTON BALL } \\
\text { VOLUME }\end{array}$ & $\begin{array}{c}.0693 \\
P=.716\end{array}$ & & $\begin{array}{c}-.3824 \\
P=.037^{\star}\end{array}$ & $\begin{array}{c}.1709 \\
P=.367\end{array}$ & $\begin{array}{c}.0951 \\
P=.617\end{array}$ & $\begin{array}{l}-.3141 \\
P=.091\end{array}$ \\
\hline $\begin{array}{l}\text { COTTON BALL } \\
\text { SPEC IF IC } \\
\text { GRAV ITY }\end{array}$ & $\begin{array}{l}-.1486 \\
P=.433\end{array}$ & $\begin{array}{c}-.3824 \\
P=.037 \\
\end{array}$ & & $\begin{array}{l}-.0532 \\
P=.780\end{array}$ & $\begin{array}{c}.1189 \\
P=.531\end{array}$ & $\begin{array}{c}.9407 \\
P=.000^{*}\end{array}$ \\
\hline $\begin{array}{l}\text { GESTAT IONAL } \\
\text { AGE }\end{array}$ & $\begin{array}{l}-.0913 \\
P=.631\end{array}$ & $\begin{array}{c}.1709 \\
P=.367\end{array}$ & $\begin{array}{l}-.0532 \\
P=.780\end{array}$ & & $\begin{array}{c}-.6832 \\
P=.000^{\star}\end{array}$ & $\begin{array}{l}-.0930 \\
P=.625\end{array}$ \\
\hline $\begin{array}{l}\text { CHRONO- } \\
\text { LOGICAL AGE }\end{array}$ & $\begin{array}{l}-.0389 \\
P=.838\end{array}$ & $\begin{array}{c}.0951 \\
P=.617\end{array}$ & $\begin{array}{c}.1189 \\
P=.531\end{array}$ & $\begin{array}{l}-.6832 \\
P=.000^{\star}\end{array}$ & & $\begin{array}{c}.1505 \\
P=.427\end{array}$ \\
\hline $\begin{array}{l}\text { PREEMIE } \\
\text { PAMPER } \\
\text { SPEC IF IC } \\
\text { GRAVITY }\end{array}$ & $\begin{array}{l}-.2320 \\
P=.217\end{array}$ & $\begin{array}{l}-.3141 \\
P=.091\end{array}$ & $\begin{array}{c}.9407 \\
P=.000^{\star}\end{array}$ & $\begin{array}{l}-.0930 \\
P=.625\end{array}$ & $\begin{array}{c}.1505 \\
P=.427\end{array}$ & \\
\hline $\begin{array}{l}\text { PREEMIE } \\
\text { PAMPER PH }\end{array}$ & $\begin{array}{c}.9310 \\
P=.000^{\star}\end{array}$ & $\begin{array}{r}.0670 \\
P=.725\end{array}$ & $\begin{array}{l}-.2565 \\
P=.171\end{array}$ & $\begin{array}{c}.0668 \\
P=.726\end{array}$ & $\begin{array}{l}-.0408 \\
P=.830\end{array}$ & $\begin{array}{l}-.2727 \\
P=.145\end{array}$ \\
\hline $\begin{array}{l}\text { PREE MI E } \\
\text { PAMPER } \\
\text { VOLUME }\end{array}$ & $\begin{array}{c}.0654 \\
P=.731\end{array}$ & & $\begin{array}{l}-.3942 \\
P=.031 *\end{array}$ & $\begin{array}{c}.1453 \\
P=.444\end{array}$ & $\begin{array}{c}.0867 \\
P=.649\end{array}$ & $\begin{array}{l}-.3283 \\
P=.077\end{array}$ \\
\hline
\end{tabular}

Significant; Critical $p \leq .05$ 
The $\mathrm{pH}$ and specific gravity results from the newborn pamper had significant differences when compared with the results from the preemie pamper or cotton ball. Therefore, newborn pamper pH and specific gravity values were correlated with the gestational age, chronological age, volume of urine in an effort to account for any differences. Gestational age was negatively correlated with chronological age (-.6832, $N=30, p=.000$ ). A weak correlation between urine $\mathrm{pH}$ and volume (.5326, $N=30, p=.002$ ) was evident. These data are depicted in Table 4. 
Table Four: Extraneous Variables and Their Correlations on Newborn Pamper Samples $(n=30)$

\begin{tabular}{|c|c|c|c|c|c|}
\hline & $\begin{array}{c}\text { CHRONO- } \\
\text { LOGICAL } \\
\text { AGE }\end{array}$ & $\begin{array}{c}\text { GESTA TI ONAL } \\
\text { AGE }\end{array}$ & $\begin{array}{l}\text { NEWBORN } \\
\text { PAMPER } \\
\text { VOLUME }\end{array}$ & $\begin{array}{l}\text { NEWBORN } \\
\text { PAMPER } \\
\text { SPEC IF IC } \\
\text { GRAVITY }\end{array}$ & $\begin{array}{c}\text { NEWBORN } \\
\text { PAMPER PH }\end{array}$ \\
\hline $\begin{array}{l}\text { CHRONO- } \\
\text { LOGICAL AGE }\end{array}$ & & $\begin{array}{c}-.6832 \\
P=.000^{\star}\end{array}$ & $\begin{array}{c}.1582 \\
P=.404\end{array}$ & $\begin{array}{l}-.0736 \\
P=.699\end{array}$ & $\begin{array}{l}-.0155 \\
P=.935\end{array}$ \\
\hline $\begin{array}{l}\text { GESTAT IONAL } \\
\text { AGE }\end{array}$ & $\begin{array}{l}-.6832 \\
P=.000^{\star}\end{array}$ & & $\begin{array}{c}.1632 \\
P=.389\end{array}$ & $\begin{array}{c}.1644 \\
P=.385\end{array}$ & $\begin{array}{c}.1714 \\
P=.365\end{array}$ \\
\hline $\begin{array}{l}\text { NEWBORN } \\
\text { PAMPER } \\
\text { VOLUME }\end{array}$ & $\begin{array}{r}.1582 \\
P=.404\end{array}$ & $\begin{array}{c}.1632 \\
P=.389\end{array}$ & & $\begin{array}{l}-.3092 \\
P=.096\end{array}$ & $\begin{array}{c}.5326 \\
P=.002^{\star}\end{array}$ \\
\hline $\begin{array}{l}\text { NEWBORN } \\
\text { PAMPER } \\
\text { SP EC IF IC } \\
\text { GRAV ITY }\end{array}$ & $\begin{array}{l}-.0736 \\
P=.699\end{array}$ & $\begin{array}{c}.1644 \\
P=.385\end{array}$ & $\begin{array}{l}-.3092 \\
P=.096\end{array}$ & & $\begin{array}{l}-.1891 \\
P=.317\end{array}$ \\
\hline $\begin{array}{l}\text { NEWBORN } \\
\text { PAMPER PH }\end{array}$ & $\begin{array}{l}-.0155 \\
P=.935\end{array}$ & $\begin{array}{c}.1714 \\
P=.365\end{array}$ & $\begin{array}{c}.5326 \\
P=.002\end{array}$ & $\begin{array}{l}-.1891 \\
P=.317\end{array}$ & \\
\hline
\end{tabular}

Significant: Critical $p \leq .05$

In an effort to determine if the infant's first 48 hours of transition to extrauterine life played a part in the results obtained for $\mathrm{pH}$ and specific gravity, the data set was altered to include only infants over 2 days of age. Since the remaining data set consisted of only 14 infants, the assumption of a normal distribution would not be warranted and 
the Wilcoxon Matched-Pairs Signed-Ranks Test was chosen to analyze this data across the 3 sampling methods (see Table 5 ). The data failed to show a significant difference in the $\mathrm{pH}$ of the newborn pamper samples when compared with that of the cotton ball or preemie pamper samples from infants who were over 2 days old. There remains a significant difference in the values for specific gravity from newborn pamper samples when compared with preemie pamper or cotton ball samples.

Table Five: Comparisons for Subjects $>2$ Days of Age: Urine PH and Specific Gravity

\begin{tabular}{|c|c|c|c|c|}
\hline $\begin{array}{l}\text { OUTCOME } \\
\text { MEASURE }\end{array}$ & $\begin{array}{l}\text { SAMPL ING } \\
\text { METHOD }\end{array}$ & $\mathbf{N}$ & 2 & 2 -TA ILED P \\
\hline PH & $\begin{array}{l}\text { COTTON BALL/ } \\
\text { NEWBORN PAMPER }\end{array}$ & 14 & -1.8904 & .0587 \\
\hline PH & $\begin{array}{l}\text { NEWBORN PAMPER/ } \\
\text { PREEM IE PAMPER }\end{array}$ & 14 & -1.6903 & .0910 \\
\hline $\begin{array}{l}\text { SPEC IF IC } \\
\text { GRAVITY }\end{array}$ & $\begin{array}{l}\text { COTTON BALL/ } \\
\text { NEWBORN PAMPER }\end{array}$ & 14 & -2.6656 & .0077 \\
\hline $\begin{array}{l}\text { SPEC IF IC } \\
\text { GRAV ITY }\end{array}$ & $\begin{array}{l}\text { NEWBORN PAMPER / } \\
\text { PREEM IE PAMPER }\end{array}$ & 14 & -2.3953 & .0166 \\
\hline
\end{tabular}

In an attempt to ascertain if the effects of the urine volume on the urine $\mathrm{pH}$ support further analysis, a $t$-test for paired samples was done on the $\mathrm{pH}$ and specific gravity of all urine samples with volumes over $20 \mathrm{~mL}$. (see Table 6). 
Significant differences in means for $\mathrm{pH}$ and specific gravities were evident between the preemie pamper and cotton ball samples. Power analysis on these data fell within 73.2-79.28.

Table Six: Comparisons of Samples With Volumes $>20 \mathrm{~mL}$.: Urine $\mathrm{PH}$ and Specific Gravity

\begin{tabular}{|c|c|c|c|c|c|c|c|c|}
\hline $\begin{array}{l}\text { OUTCOME } \\
\text { MEASURE }\end{array}$ & $\begin{array}{l}\text { SA MP LE } \\
\text { ME THOD }\end{array}$ & $\mathbf{N}$ & CORR. & MEAN & SD & $t$ & $d f$ & $\begin{array}{l}2- \\
\text { TAIL } \\
\text { SIG. }\end{array}$ \\
\hline PH & $\begin{array}{l}\text { COTTON BALL/ } \\
\text { NEHBORN PAMPER }\end{array}$ & 23 & .567 & $\begin{array}{l}6.1304 \\
5.5652\end{array}$ & $\begin{array}{l}.694 \\
.728\end{array}$ & 4.09 & 22 & .000 \\
\hline $\mathrm{PH}$ & $\begin{array}{l}\text { NEWBORN PAMPER/ } \\
\text { PREEMIE PAMPER }\end{array}$ & 23 & .585 & $\begin{array}{l}5.5652 \\
6.0870\end{array}$ & $\begin{array}{l}.728 \\
.733\end{array}$ & -3.76 & 22 & .001 \\
\hline $\begin{array}{l}\text { SPEC IF IC } \\
\text { GRAVITY }\end{array}$ & $\begin{array}{l}\text { NEHBORN PAMPER / } \\
\text { PREEMIE PAMPER }\end{array}$ & 23 & .222 & $\begin{array}{l}1.0135 \\
1.0065\end{array}$ & $\begin{array}{l}.006 \\
.003\end{array}$ & 5.72 & 22 & .000 \\
\hline $\begin{array}{l}\text { SPEC IF IC } \\
\text { GRAV ITY }\end{array}$ & $\begin{array}{l}\text { COTTON BALL/ } \\
\text { NEHBORN PAMPER }\end{array}$ & 23 & .354 & $\begin{array}{l}1.0063 \\
1.0135\end{array}$ & $\begin{array}{l}.003 \\
.006\end{array}$ & -6.37 & 22 & .000 \\
\hline
\end{tabular}




\section{CHAPTER FIVE}

\section{Discussion}

The study findings support the use of a cotton ball for collection of urine for LPA and labstick analysis. The major concern related to the LPA specimen collection method has been the incidence of false positives. The single subject who tested positive for LPA but had a negative blood culture might have been an early detection (Becton Dickinson, 1993) prior to full blown sepsis, or that the amount of blood collected for blood cultures might have been too small for detection (Sanchez et. al.,1990). The results with the cotton ball method were at least as effective as the costly, more invasive catheterization technique.

The results obtained from the newborn samples were similar to those from the preemie pamper and cotton ball with respect to the presence of blood, glucose and protein. The differences may be accounted for by the timing of the sampling and the dynamic state of the infant cared for in the NICU. The parameters that were negative (bilirubin, ketones, leukocytes, nitrites and urobilinogen) correlated across the three sampling methods. No strong, significant correlation was evident between the newborn urine sample $\mathrm{pH}$ or specific gravity results when compared to the preemie pamper or cotton ball results. When analysis was done to determine if infants 
over 2 days of age would have urine values that correlated across the sampling methods, a significant difference in specific gravity was demonstrated. There was a slight improvement in the correlation of $\mathrm{pH}$ when the volume of urine was $>20 \mathrm{~mL}$. . It is possible that the newborn pamper contains absorbent material that has an acidic $\mathrm{pH}$ which is influencing the samples. If this is the case, the larger volumes of urine would dilute the effects of the acidic environment, yielding more accurate results. The maturation process and the ability of the older infant to retain bicarbonate (Richardson, 1991) may also help account for this difference. The numbers involved $(N=14)$ are small, however, and caution should be exercised in interpreting this data.

\section{Limitations}

The infants in this study were not the extremely premature infants who pose the greatest challenge to skin care. The implementation of cotton ball sampling must be made with careful assessment of its impact on the skin integrity of the less mature infants.

A single cotton ball sample for LPA that was read as "not interpretable" by laboratory personnel. The director of the microbiology laboratory stated that there was something that interfered with the test. She described urinary sediment of cotton fibers as possible sources of the interference. Laboratory personnel involved could not interpret the test as 
such, and this subject was eliminated from the analysis, but should remain in our consideration should replication of this study be attempted. The small sample size with only three positive results limits the power of this study. Furthermore, maternal cultures were not available on 14 of the 20 infants. Based on Zeichner and Plotkin's (1988) estimate that incidence of GBS in the pregnant population approaches $30 \%$, it would be assumed that this would be true of this sample.

There were very few subjects with positive results on the biochemical portion of the labstick analysis (blood, $N=2$; glucose, $N=2$; protein, $N=5$ ) to lend strength to this analysis. This limits the generalizability of the study. It cannot be assumed that the presence of bilirubin, ketones, leukocytes, nitrites or urobilinogen would test accurately across the sampling techniques without investigation.

The environment in which the cotton ball is placed for sample collection may be a factor to be explored. It is already known that in order for the results to be accurate, the diaper must remain closed (Stebor, 1989) (Lybrand, MedoffCooper and Munro, 1990). With the many newborn, preemie and the "wee pee" diapers currently available, there is a possibility that the type of material in the diaper will affect the cotton ball results, lending further investigation. Additionally, the infants in this study were not the extremely premature infants so commonly cared for in the NICU. It is possible that the differences in these infants with respect to 
their skin thickness and fluids lost via the skin might influence the results of the labstick analysis.

\section{Future Research}

Future research is warranted to include infants less than 1000 grams. Assessment of the effects of the cotton ball on the skin of these infants must be on-going as the population cared for becomes less mature and increasingly vulnerable.

Replication of the LPA study in a larger sample is warranted. The small number of positive results (3) limits the power of this study. Furthermore, correlation with maternal cultures would enhance the generalizability of the results.

Replication of the labstick analysis on urine samples from populations known to have a higher incidence of blood, bilirubin, glucose, ketones, leukocytes, nitrites, protein, and urobilinogen in their urine would be of interest. Alternatively, the substances used to run control tests in the laboratory could be used. A sample with a known quantity of the biochemical substance to be analyzed could be introduced into the cotton ball. A sample could then be removed and analyzed to assure accuracy.

The effects the diaper brand has on the cotton ball maintained within over a three-hour period is another area to be explored. If the super-absorbent gel materials contribute to lower $\mathrm{pH}$ and higher specific gravity in samples taken from 
the newborn pamper, the cotton ball sample may also be altered.

Lastly, other tests that may require a urine sample (toxicology, for example) need to be investigated. The potential for sample collection via the cotton ball could be expanded to include other laboratory tests once this has been tested.

\section{Implications}

Despite these limitations and the need for further research, the data support the cotton ball method. It has the potential to replace the more expensive and traumatic urine bag applications, bladder catheterizations, and suprapubic taps. However, in order to assure accuracy of the sample, a thorough cleansing of the diaper area must consistently precede sampling.

The simplification of urine collection method can save on nursing hours and costly medical supplies. In today's health care crisis, these benefits are important. The benefit to the infant of a safer, less traumatic process is of paramount importance.

The samples collected from the super-absorbent newborn pampers demonstrated the need to research new methods prior to their introduction into practice. The method tested has been accepted and even published in nursing references as a method to sample urine. It can provide information on the presence of 
blood, glucose and protein with some degree of accuracy, but the values for $\mathrm{pH}$ and specific gravity are not dependable. It would be imprudent to go on basing treatment of newborns, who require intensive care and accurate assessments, on urine samples collected from newborn super-absorbent pampers. 


\section{BEFERENCES}

American Nurses Association (1985). Human Rights Guidelines for Nurses in Clinical and Other Research, Washington, D.C.

Ahmad, T., Vickers, D., Campbell, S., Coulthard, M., Pedler, S. (1991). Urine collection from disposable nappies. The Lancet; 338: 674-76.

Barkemeyer, B. (1993). Suprapubic aspiration of urine in very low birth weight infants. Pediatrics; 29(3) :457-9.

Becton Dickinson Microbiology Systems. (1993). Directigen Meningitis Individual Tests. Becton Dickinson and Co.; Cockeysville, Md.: 1-6.

Behrman, R. and Vaughan, V. (1987). Nelson Textbook of Pediatrics (13th ed.), Nelson, W. ed., W. B. Saunders Co.; Philadelphia: 1552.

Berram, M. and Dhanireddy, R. (1991). Urinalysis: direct versus diaper collection. Clinical Pediatrics; $30(\underline{5}): 278-280$.

Boehringer Mannheim Diagnostics. (1990). Chemstrip 10 With SG Urine Test Strips. Boehringer Mannheim Corp; Indianapolis.

Cohen, J. (1977). Statistical Power Analysis for the Behavieral Sciences. Academic Press, Inc., Orlando.

Cooke, R. (1989). Urine output measurements in preterm infants. Pediatrics; 83(1): 116-8.

Dempsey, P. and Dempsey, A. (1992). Nursing Research with Basic Applications; Jones and Bartlett Publications; Boston: $56-112,143-180$.

Fletcher, M. and MacDonald, M. (1993). Atlas of Procedures in Neonatology; J. B. Lippincott, Co.; Philadelphia: 118-125.

Fox, M. (1992). Measurement of urine output volume: accuracy of diaper weights in the neonatal environment. Neonatal Network; $11(\underline{2})$ : $11-18$.

Gammage, D. and Yarandi, H. (1993). The effects of diaper brands, urine volume, and time on specific gravity measurement. Journal of Pediatric Nursing; 8(1): 10-14.

Hutton, N. and Schreiner, R. (1980). Urine collection in the neonate: effect of different methods on volume, specific gravity and glucose. JOGN Nursing, $9(\underline{3})$ : 165-169. 
Isaacs, $D$ and Moxon, $E$. (1991). Neonatal Infections; Butterworth-Heinmann, Ltd; Oxford: 6-7, 36-7.

Kuller, J. (1984). Skin care in the intensive care nursery, part one, skin development and function. Neonatal Network; $3(\underline{3}): 18-23$.

Kuller, J. and Tobin, C. (1990). Skin care management of the low-birthweight infant. In Care of the 24-25 Week Gestational Age Infant (Small Baby Protocol), Gunderson, L. and Kenner, C., eds., Neonatal Network; Petaluma, Ca.: 97-128.

Kuller, J. and Lund, C. (1993). Assessment and management of integumentary dysfunction. In Comprehensive Neonatal Nursing: A Physiologic Perspective, Kenner, C., Brueggemeyer, A., and Gunderson, L., eds., W. B. Saunders Co.; Philadelphia: 742-81.

Lloyd, C. (1993). Making sense of reagent strip testing, Nursing Times; $89(\underline{48}): 34-6$.

Lybrand, M., Medoff-Cooper, B., and Munro, B. (1990). Periodic comparisons of specific gravity using urine from a diaper and collecting bag. MCN; 15: $238-9$.

McCourt, M. (1994). At risk for infection: the very-low-birthweight infant. JOPN Nursing; 7(4): 52-64.

Merenstein, G. and Gardner, S. (1985). Handbook of Neonatal Intensive Care, C. V. Mosby Co.; St. Louis: 63, 163-178.

NAACOG. (1992) Neonatal skin care. OGN Nursing Practice Guideline; Washington,D.C.: 1 -9.

Polin, R. and speck, W. (1991). Neonatal sepsis. Clinics in Perinatology; $18(\underline{2})$ : $368-9$.

Polit, D and Hungler, B. (1991). Nursing Research, J. B. Lippincott Co.; Philadelphia.

Reams, P. and Dean, D. (1988). Bagged versus diaper urine specimens and laboratory values. Neonatal Network; 6(6): 17 20.

Richardson, K. (1991). Renal function in the preterm neonate: an overview. Neonatal Network; 10() : 17-23.

Sanchez, P., Seigel, J., Cushion, N., Trelkeld, N. (1990). Significance of a positive urine group B streptococcal latex agglutination test in neonates. Jeurnal of Pediatrics; 116(4): $601-6$. 
Schlager, T., Dunn, M., Dudley, S. and Lohr, J. (1990). Bacterial contamination rate of urine collected in a urine bag from healthy non-toilet-trained male infants. Jeurnal of Pediatries; 116(5): $738-9$.

Stebor, A. (1989). Posturination time and specific gravity in infants' diapers. Nursing Research; $38(4): 244-5$.

Suri, S. (1988). Simplifying urine collection from infants and children without loosing accuracy. MCN; 13: 438-41.

Tobin, C. (1984): Skin care in the intensive care nursery, part two, dispelling common myths. Neonatal Network; $3(\underline{3}): 25$ 27.

Wilson, H. (1987). Introducing Research in Nursing; AddisonWesley Publishing Co., Menlo Park, Ca.

Wong, D. and Whaley, L. (1990). Clinical Manual of Pediatric Nursing; C.V. Mosby, Co., St. Louis: 221.

Wong, D., Brantley, D., Clutter, L., De Simons, D. , Lammert, D., Nix, K., Perry, K., Smith, D., White, K. (1992). Diapering choices: a critical review of the issues. Pediatric Nursing; $18(1): 41-54$.

Zeichner, S. and Plotkin, S. (1988). Mechanisms and pathways of congenital infections. In B. J. Freij and J. L. Sever (Eds.), Infectious Complications of Pregnancy; W. B. Saunders Co., Philadelphia: 163-188. 


\section{Informed consent}

\section{Newborn Urine Sampling Methods}

In signing this form, I consent to allow the investigators involved in this research project to review the results of my son/daughter's urine test results that are routinely collected in the NICU at South Miami Hospital. The standard methods currently used to collect urine will be compared with a cotton ball aspiration technique described in order to see if this alternative method can be accurate.

The results to be compared include:

1.) The presence of a substance that indicates exposure to infection

2.) The presence of blood, glucose, ketones, nitrite, urobilinogen, bilirubin, protein, $\mathrm{Ph}$ and specific gravities, all of which give an indication of the baby's status and guide in treatment.

These tests are routinely performed on infants admitted to the $N I C U$, regardless of their participation in this study.

We plan to sample the urine by standard methods currently in use, which include:

1.) Insertion of a small, lubricated tube (catheter) under sterile conditions into the urinary opening after thoroughly cleansing the area. This is a standard procedure and is carried out regardless of consent to enroll your infant in this study. The results will be compared with a sample obtained by placing a cotton ball at the urinary opening, which will then be removed and a urine sample aspirated for comparison. This is a one time occurrence. It is hoped that the results of this study will enable us to use the cotton ball method to collect urine samples of this nature, thus decreasing the invasive nature and cost of the catheter sampling method currently in use.

2.) Currently, diapers containing urine are aspirated and the urine sample is tested routinely in the NICU at least once every 12 hours. This is standard procedure and will be carried out regardless of consent to enroll your infant in the study. The results will be compared with a sample obtained by placing a cotton ball at the urinary opening, which will then be removed and urine sample aspirated for comparison. We hope to establish accuracy of this sampling method.

These comparisons will not involve any additional risk to your baby, nor will the cost of the redundant lab test be passed on to you or your insurance company. Identification of the infant and results will remain within the investigative committee, and will not be a part of the published results. 
This consent is needed in order to allow us to carry out the comparison studies and share the results among investigators. Because the subject is a minor and especially vulnerable, we recognize the need to protect them from harm and insure confidentiality. The research review board at florida International University has examined this study design to insure this will be maintained. Participation in this study is voluntary, and treatment of your infant will not depend on entry into the study. Any questions can be directed to:

Nancy Burke, RNC, BSN at 312-6016 (digital beeper) Jorge Perez, MD, Critical Care Newborn Services at 661-1515 Luz Porter, PhD, RN, Professor F.I.U. at 940-5971

Signature

Relationship Date

Patient's name

Witness

A copy of this form is available upon request. 


\section{FLORIDA INTERNATIONAL UNIVERSITY}

Miami, Florida

PROPOSAL FOR RESEARCH THESIS

MASTER OF SCIENCE IN NURSING

SCHOOL OF NURSING

ADVANCED CHILD HEALTH NURSING

Nancy Ann Burke

I propose to the Major Professor and to the Committee Members a study to be conducted in partial fulfillment of the requirements for the degree of Master of Science in Nursing: ALTERNATIVE METHODS FOR NEWBORN URINE SAMPLE COLLECTION. 


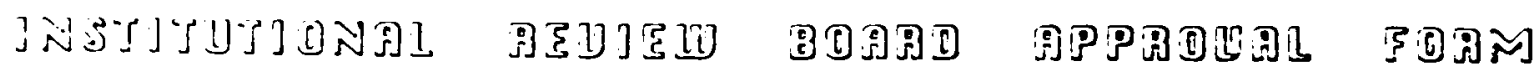

\section{FLORIDA INTERNATIONAL UNIUERSITY \\ University Park Campus \\ Miami, Florida 33199}

This is to certify that the program listed below has been reviewed and approved/denied by the Institutional Review Board (IRB) in accordance with the requirements of 45 CFR 46 , including its releuant subparts.

Principal Investigator/Project Director: Nanc: Burke/Luz Porter

Title of Application: Altenative Methods for Vewicorn Urine Sample Collection

Rgency Submitted to:

Proposal Identification Number (if auailable):

Certificate of IRB:

$9: 2=294$

Date of IRB Review and Approuay/dDenial

$\mathrm{X}$ Full Board Reuiew

Expedited Review

Comments: Study ras deferred pencing more information about exact: $\because$ inat is

stanciara crocejure at riami jospital. If this is rouline procecure, then the study j5 apsroved.

Any problems should be immediately brought to the attention of the IRB Council

The official signing below certifies that the information on this form is correct and the institution assumes responsibility for assuring future reviews, approuais, and submissiogs of certification.

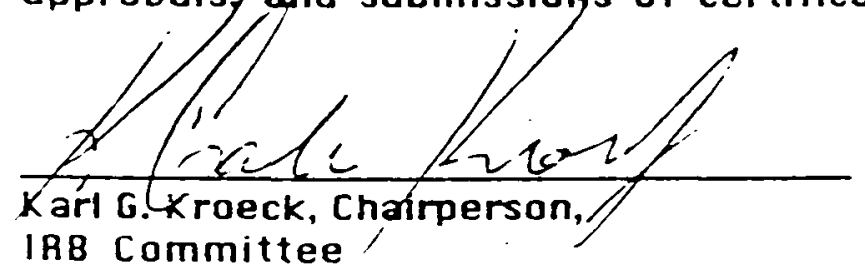

Apfisais

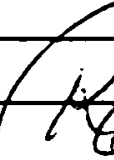


September 27, 1994

Nancy Burke, R.N.

7001 S.W. 70 Avenue

Miami, FL 33143

\title{
RE: Alternate Methods for Newborn Urine Sample Collection
}

\section{Dear Nancy,}

This letter is to confirm that the Institutional Review Board reviewed and approved the above named protocol and informed consent on September 23, 1994. It is the responsibility of the Principal Investigator to notify the I.R.B. in writing within 5 days of occurrence of any adverse events experience $j$ by patients participating in the study, and to provide written updates of study progress at 6 month intervals.

The F.D.A. has explicit guidelines regarding advertising for the purpose of recruiting study subjects. As the Principal Investigator, you are responsible for ensuring that you have I.R.B. approval for the text or script to be used in advertising before the advertising is released. Failure to obtain I.R.B. approval of advertising materials will result in withdrawal of I.R.B. approval for the study.

It is the responsibility of the Principal Investigator to ensure that additional charges for tests, procedures, or services incurred by the patient as a result of participation in this study are reimbursed to the hospital by either the Investigator or the Sponsor.

Enclosed for your reference are the F.D.A. guidelines and a copy of the current I.R.B. Membership Roster.

\author{
Sincerely.

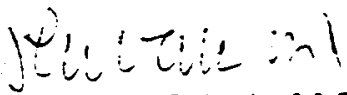 \\ Jeremy I. Tabak, M.D. \\ Chairman \\ Institutional Review Board
}

cc. Melanie Mitrani, R.N.. I.R.B. Coordinator 
Date: October 13,1994

Memo: Nancy Burke, R.N.

From: Gwen Young, R.N.M.S.N. R'-1

Chairperson, Nursing Research Committee

The Nursing Research Committee have reviewed your proposal and have granted permission for you to start data collection at South Miami Hospital at your convenience.

Please send us a copy of the completed study and feel free to contact us if we can be of further assistance. 